\title{
Modelling the Boronizing Kinetics in AISI 316 Stainless Steel
}

\author{
Z. Nait Abdellah ${ }^{a, b}$, M. Keddam ${ }^{b, *}$ And A. Elias ${ }^{a}$
}

${ }^{a}$ Département de Chimie, Faculté des Sciences, Université Mouloud Mammeri, 15000, Tizi-Ouzou, Algeria

${ }^{b}$ Laboratoire de Technologie des Matériaux, Département de SDM, Faculté de Génie Mécanique

et Génie des Procédés, USTHB, B.P. Nº32, 16111, El-Alia, Bab-Ezzouar, Algiers, Algeria

This work deals with the simulation of the growth kinetics of the $\left(\mathrm{FeB} / \mathrm{Fe}_{2} \mathrm{~B}\right)$ bilayer and the diffusion zone on a substrate of AISI 316 stainless steel exposed to the powder-pack boriding process, in the temperature range of $1123-1273 \mathrm{~K}$ and a time duration ranging from 2 to $10 \mathrm{~h}$. The developed diffusion model employs a set of mass balance equations at the three growth fronts: [ $\left.\mathrm{FeB} / \mathrm{Fe}_{2} \mathrm{~B}\right),(\mathrm{FeB} /$ diffusion zone) and (diffusion zone/substrate)] under certain assumptions, including the effect of the incubation times during the formation of iron borides and the diffusion zone. For this purpose, a computer code written in Matlab (version 6.5) was created to simulate the boriding kinetics. A good concordance was obtained when comparing the experimental parabolic growth constants taken from the literature and the simulated values of the parabolic growth constants: $\left(k_{\mathrm{FeB}}, k_{1}\right.$ and $\left.k_{2}\right)$. Moreover, the present model was also used to predict the thicknesses of the $\mathrm{FeB}$ and $\mathrm{Fe}_{2} \mathrm{~B}$ layers and the diffusion zone thickness at various treatment times and boriding temperatures. The simulated values were in good agreement with the experimental borided layers thicknesses.

PACS: 81.15.Aa, 68.55.A-, 68.47.De, 68.55.jd

\section{Introduction}

The boriding (or boronizing) process is widely used in the industry to improve the corrosion resistance, tribological and mechanical properties of the treated surfaces of parts [1]. The surfaces of samples from the AISI 316 steel must be mechanically polished, and cleaned with an organic solvent, to remove the $\mathrm{Cr}$ oxide on the surfaces before boriding. Such a surface preparation is necessary to allow the boron diffusion in case of the borided AISI 316 stainless steel. Depending on the process temperature, the chemical composition of the material substrate, the boron potential of medium and the boriding time, either one iron boride $\left(\mathrm{Fe}_{2} \mathrm{~B}\right)$ or two iron borides $(\mathrm{FeB}+$ $\mathrm{Fe}_{2} \mathrm{~B}$ ) are formed by diffusing boron atoms into the surface of ferrous substrates. The presence of alloying elements such as $\mathrm{Cr}, \mathrm{Mo}, \mathrm{Ni}$ and $\mathrm{V}$ modifies the morphology of the boride layers. These substitutional elements tend to concentrate at the tips of the boride needles. The concentration of these elements reduces the active boron flux in this zone and diminishes the boride layer thickness. Consequently, the (boride layer/diffusion zone) interface tends to be flat [2]. Diffusion processes play a key role in the kinetics of the boriding process. In a practical point of view, the experimental approach to studying the growth kinetics of the generated diffusion coatings is widely accompanied by the use of mathematical simulation.

In the present work, a comprehensive diffusion model, based on solving the mass balance equations at the growth interfaces, was proposed to simulate the growth kinetics of the $\left(\mathrm{FeB} / \mathrm{Fe}_{2} \mathrm{~B}\right)$ bilayer and the diffusion zone. This present kinetic model is an extended version of that

\footnotetext{
* corresponding author; e-mail: keddam@yahoo.fr
}

recently published [3]. The suggested diffusion model was used to compare the experimental parabolic growth constants at the growth interfaces [4] with the simulated parabolic growth constants. The predicted values of parabolic growth constants at each phase interface and the simulated borided layers thicknesses coincide well with the experimental data available in the reference work [4].

\section{The boron diffusion model}

A schematic boron depth-concentration profile through the $\left(\mathrm{FeB} / \mathrm{Fe}_{2} \mathrm{~B}\right)$ bilayer and the diffusion zone on a saturated substrate with boron atoms is displayed in Fig. 1. $C_{\mathrm{up}}^{\mathrm{FeB}}$ and $C_{\mathrm{low}}^{\mathrm{FeB}}(=16.23 \mathrm{wt} \% \mathrm{~B})$ are the upper and lower limits of boron content in the $\mathrm{FeB}$ layer, respectively, while $C_{\mathrm{up}}^{\mathrm{Fe}_{2} \mathrm{~B}}(=9 \mathrm{wt} \% \mathrm{~B})$ and $C_{\text {low }}^{\mathrm{Fe}_{2} \mathrm{~B}}$

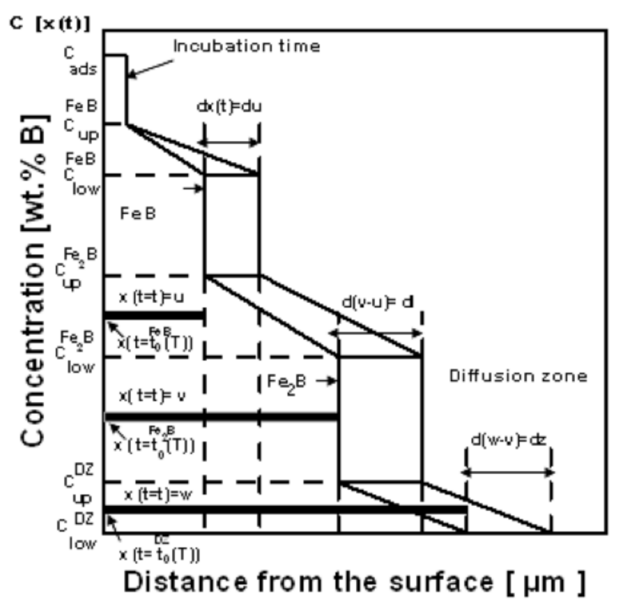

Fig. 1. A schematic boron depth-concentration profile through the $\left(\mathrm{FeB} / \mathrm{Fe}_{2} \mathrm{~B}\right)$ bilayer and the diffusion zone. 
$(=8.83 \mathrm{wt} \% \mathrm{~B})$ are the same limits in the $\mathrm{Fe}_{2} \mathrm{~B}$ layer [5-7]. $C_{\text {up }}^{\mathrm{DZ}}\left(=35 \times 10^{-4} \mathrm{wt} \% \mathrm{~B}\right)$ denotes the upper limit of boron content within the diffusion zone [8]. $C_{\text {low }}^{\mathrm{DZ}}$ $(\approx 0 \mathrm{wt} \% \mathrm{~B})$ represents the lower limit of boron content in the diffusion zone. The three parameters: $t_{0}^{\mathrm{FeB}}(T)$, $t_{0}^{\mathrm{Fe}_{2} \mathrm{~B}}(T)$ and $t_{0}^{\mathrm{DZ}}(T)$ are the boride incubation times. The term $C_{\text {ads }}$ denotes the adsorbed concentration of boron [9]. $u$ is the position of the $\left(\mathrm{FeB} / \mathrm{Fe}_{2} \mathrm{~B}\right)$ interface, $v$ - the position of the $\left(\mathrm{Fe}_{2} \mathrm{~B} /\right.$ diffusion zone) interface and $w$ - the position of the (diffusion zone/substrate) interface. The upper boron content in the FeB phase $\left(C_{\mathrm{up}}^{\mathrm{FeB}}\right)$ is linked to the boron potential, imposed by the chemical composition of the powder mixture. Its value is located between two limits, 16.23 and $16.43 \mathrm{wt} \% \mathrm{~B}$, where it is reported that the $\mathrm{FeB}$ phase has a narrow composition range of about ( 1 at.\%B $)$ or $(0.2 \mathrm{wt} \% \mathrm{~B})$ [10].

The assumptions taken into account during the formulation of the diffusion model can be found elsewhere [3]. The initial and boundary conditions of the diffusion problem were established as

$$
\begin{aligned}
& C_{\mathrm{FeB}}[x(t>0)=0]=0, \quad C_{\mathrm{Fe}_{2} \mathrm{~B}}[x(t>0)=0]=0, \\
& C_{\mathrm{DZ}}[x(t>0)=0]=0 .
\end{aligned}
$$

The boundary conditions are given by the following equations:

$$
C_{\mathrm{FeB}}\left\{x\left[t=t_{0}^{\mathrm{FeB}}(T)\right]=0\right\}=C_{\mathrm{up}}^{\mathrm{FeB}},
$$

for $C_{\text {ads }}>16.23 \mathrm{wt} \% \mathrm{~B}$;

$$
C_{\mathrm{FeB}}\left\{x\left[t=t_{0}^{\mathrm{FeB}}(T)\right]=0\right\}=C_{\mathrm{low}}^{\mathrm{FeB}},
$$

for $C_{\text {ads }}<16.23 \mathrm{wt} \% \mathrm{~B}$ and with FeB phase;

$$
C_{\mathrm{Fe}_{2} \mathrm{~B}}\left\{x\left[t=t_{0}^{\mathrm{Fe}_{2} \mathrm{~B}}(T)\right]=0\right\}=C_{\mathrm{up}}^{\mathrm{Fe}_{2} \mathrm{~B}},
$$

for $8.83 \mathrm{wt} \% \mathrm{~B}<C_{\mathrm{ads}}<16.23 \mathrm{wt} \% \mathrm{~B}$ and without $\mathrm{FeB}$ phase;

$$
C_{\mathrm{Fe}_{2} \mathrm{~B}}\left\{x\left[t=t_{0}^{\mathrm{Fe}_{2} \mathrm{~B}}(T)\right]=0\right\}=C_{\text {low }}^{\mathrm{Fe}_{2} \mathrm{~B}},
$$

for $C_{\text {ads }}<8.83$ wt $\% \mathrm{~B}$ and without FeB phase;

$$
C_{\mathrm{DZ}}\left\{x\left[t=t_{0}^{\mathrm{DZ}}(T)\right]=0\right\}=C_{\mathrm{up}}^{\mathrm{DZ}},
$$

for $35 \times 10^{-4} \mathrm{wt} \% \mathrm{~B}<C_{\mathrm{ads}}<8.83 \mathrm{wt} \% \mathrm{~B}$ and without $\mathrm{Fe}_{2} \mathrm{~B}$ phase;

$$
C_{\mathrm{DZ}}\left\{x\left[t=t_{0}^{\mathrm{DZ}}(T)\right]=0\right\}=C_{\mathrm{low}}^{\mathrm{DZ}},
$$

for $C_{\text {ads }}<35 \times 10^{-4} \mathrm{wt} \% \mathrm{~B}$ and without $\mathrm{Fe}_{2} \mathrm{~B}$ phase;

$$
\begin{aligned}
& C_{\mathrm{FeB}}(x(t=t)=u)=C_{\mathrm{low}}^{\mathrm{FeB}}, \\
& C_{\mathrm{Fe}_{2} \mathrm{~B}}(x(t=t)=u)=C_{\mathrm{up}}^{\mathrm{Fe}_{2} \mathrm{~B}}, \\
& C_{\mathrm{Fe}_{2} \mathrm{~B}}(x(t=t)=v)=C_{\mathrm{low}}^{\mathrm{Fe}_{2} \mathrm{~B}}, \\
& C_{\mathrm{DZ}}(x(t=t)=v)=C_{\mathrm{up}}^{\mathrm{DZ}}, \\
& C_{\mathrm{DZ}}(x(t=t)=w)=C_{\mathrm{low}}^{\mathrm{DZ}} .
\end{aligned}
$$

The mass balance equations through the considered growth fronts [11] are described by the following set of Eqs. (13), (14) and (15):

$$
\begin{gathered}
w_{\mathrm{FeB}} \frac{\mathrm{d} u}{\mathrm{~d} t}=D_{\mathrm{B}}^{\mathrm{FeB}} \frac{C_{\mathrm{up}}^{\mathrm{FeB}}-C_{\mathrm{low}}^{\mathrm{FeB}}}{u} \\
-D_{\mathrm{B}}^{\mathrm{Fe}_{2} \mathrm{~B}} \frac{C_{\mathrm{up}}^{\mathrm{Fe}_{2} \mathrm{~B}}-C_{\mathrm{low}}^{\mathrm{Fe}_{2} \mathrm{~B}}}{l},
\end{gathered}
$$

$$
\begin{gathered}
w_{\mathrm{Fe}_{2} \mathrm{~B}} \frac{\mathrm{d} v}{\mathrm{~d} t}+\sigma_{1} \frac{\mathrm{d} u}{\mathrm{~d} t}=D_{\mathrm{B}}^{\mathrm{Fe}_{2} \mathrm{~B}} \frac{C_{\mathrm{up}}^{\mathrm{Fe}_{2} \mathrm{~B}}-C_{\mathrm{low}_{2} \mathrm{~B}}^{\mathrm{Fe}_{2}}}{l} \\
-D_{\mathrm{B}}^{\mathrm{DZ}} \frac{C_{\mathrm{up}}^{\mathrm{DZ}}-C_{\mathrm{low}}^{\mathrm{DZ}}}{z}, \\
\sigma_{2}\left(\frac{\mathrm{d} w}{\mathrm{~d} t}-\frac{\mathrm{d} u}{\mathrm{~d} t}\right)=D_{\mathrm{B}}^{\mathrm{DZ}} \frac{C_{\mathrm{up}}^{\mathrm{DZ}}-C_{\mathrm{low}}^{\mathrm{DZ}}}{z},
\end{gathered}
$$

with $w_{\mathrm{FeB}}=0.5\left(C_{\mathrm{up}}^{\mathrm{FeB}}+C_{\text {low }}^{\mathrm{FeB}}\right)-C_{\mathrm{up}}^{\mathrm{Fe}_{2} \mathrm{~B}}, w_{\mathrm{Fe}_{2} \mathrm{~B}}=$ $0.5\left(C_{\mathrm{up}}^{\mathrm{Fe}_{2} \mathrm{~B}}+C_{\text {low }}^{\mathrm{Fe}_{2} \mathrm{~B}}\right)-C_{\mathrm{up}}^{\mathrm{DZ}}, \sigma_{1}=0.5\left(C_{\mathrm{up}}^{\mathrm{Fe}_{2} \mathrm{~B}}-C_{\text {low }}^{\mathrm{Fe}_{2} \mathrm{~B}}\right)$, $\sigma_{2}=0.5\left(C_{\mathrm{up}}^{\mathrm{DZ}}-C_{\text {low }}^{\mathrm{DZ}}\right), D_{\mathrm{B}}^{\mathrm{FeB}}, \quad D_{\mathrm{B}}^{\mathrm{Fe}_{2} \mathrm{~B}}$ and $D_{\mathrm{B}}^{\mathrm{DZ}}$ are the diffusion coefficients of boron in the $\mathrm{FeB}$ and $\mathrm{Fe}_{2} \mathrm{~B}$ iron borides, and in the diffusion zone, respectively. The FeB layer thickness $u$ obeys to a parabolic growth law according to Eq. (16), where $k_{\mathrm{FeB}}$ is the parabolic growth constant at the $\left(\mathrm{FeB} / \mathrm{Fe}_{2} \mathrm{~B}\right)$ interface

$$
u=k_{\mathrm{FeB}}\left[t-t_{0}^{\mathrm{FeB}}(T)\right]^{0.5} \text {. }
$$

The distance, $v$, is the location of the $\left(\mathrm{Fe}_{2} \mathrm{~B} /\right.$ substrate $)$ interface and $k_{1}$ its parabolic growth constant given by Eq. (17) and the difference $(l=v-u)$ denotes the layer thickness of $\mathrm{Fe}_{2} \mathrm{~B}$ expressed by Eq. (18):

$$
\begin{aligned}
v & =k_{1}\left[t-t_{0}^{\mathrm{Fe}_{2} \mathrm{~B}}(T)\right]^{0.5}, \\
l & =v-u=k_{1}\left[t-t_{0}^{\mathrm{Fe}_{2} \mathrm{~B}}(T)\right]^{0.5} \\
& -k_{\mathrm{FeB}}\left[t-t_{0}^{\mathrm{FeB}}(T)\right]^{0.5},
\end{aligned}
$$

with $t_{0}^{\mathrm{FeB}}(T)>t_{0}^{\mathrm{Fe}_{2} \mathrm{~B}}(T)$ and $k_{1}>k_{\mathrm{FeB}}$. The distance, $w$, is the location of the (diffusion zone/substrate) interface and $k_{2}$ its parabolic growth constant given by Eq. (19) and the difference $(z=w-v)$ is the layer thickness of the diffusion zone expressed by Eq. (20):

$$
\begin{aligned}
w & =k_{2}\left[t-t_{0}^{\mathrm{DZ}}(T)\right]^{0.5} \\
z & =w-v=k_{2}\left[t-t_{0}^{\mathrm{DZ}}(T)\right]^{0.5} \\
& -k_{1}\left[t-t_{0}^{\mathrm{Fe}_{2} \mathrm{~B}}(T)\right]^{0.5},
\end{aligned}
$$

with $t_{0}^{\mathrm{Fe}_{2} \mathrm{~B}}(T)>t_{0}^{\mathrm{DZ}}(T)$ and $k_{2}>k_{1}>k_{\mathrm{FeB}}$. The diffusion coefficients of boron in each iron boride and in the diffusion zone (in $\mathrm{m}^{2} / \mathrm{s}$ ) were taken from Ref. [4], and they are given by Eqs. (21), (22) and (23):

$$
\begin{aligned}
& D_{\mathrm{B}}^{\mathrm{FeB}}=1 \cdot 1 \times 10^{-3} \exp \left(\frac{-204 \mathrm{~kJ} / \mathrm{mol}}{R T}\right), \\
& D_{\mathrm{B}}^{\mathrm{Fe}_{2} \mathrm{~B}}=5 \cdot 7 \times 10^{-4} \exp \left(\frac{-198 \mathrm{~kJ} / \mathrm{mol}}{R T}\right), \\
& D_{\mathrm{B}}^{\mathrm{DZ}}=1 \cdot 7 \times 10^{-9} \exp \left(\frac{-116 \mathrm{~kJ} / \mathrm{mol}}{R T}\right),
\end{aligned}
$$

where $R$ is the universal gas constant (= $8.314 \mathrm{~J} /(\mathrm{mol} \mathrm{K}))$, and $T$ represents the absolute temperature. The set of Eqs. (13), (14) and (15) can be transformed into Eqs. (24), (25) and (26):

$$
\begin{aligned}
& k_{\mathrm{FeB}}^{2} w_{\mathrm{FeB}}\left[k_{1}-k_{\mathrm{FeB}} \phi(T)\right]=2 D_{\mathrm{B}}^{\mathrm{FeB}}\left(C_{\mathrm{up}}^{\mathrm{FeB}}-C_{\mathrm{low}}^{\mathrm{FeB}}\right) \\
& \quad \times\left[k_{1}-k_{\mathrm{FeB}} \phi(T)\right] \\
& \quad-2 \phi(T) D_{\mathrm{B}}^{\mathrm{Fe}_{2} \mathrm{~B}}\left(C_{\mathrm{up}}^{\mathrm{Fe}_{2} \mathrm{~B}}-C_{\mathrm{low}}^{\mathrm{Fe}_{2} \mathrm{~B}}\right) k_{\mathrm{FeB}},
\end{aligned}
$$




$$
\begin{aligned}
& {\left[k_{1}-k_{\mathrm{FeB}} \phi(T)\right]\left[k_{2}-k_{1} \eta(T)\right]\left[\left(\sigma_{1}-\sigma_{2}\right) k_{\mathrm{FeB}}\right.} \\
& \left.\quad+w_{\mathrm{Fe}_{2} \mathrm{~B}} k_{1} \phi(T)+\sigma_{2} k_{2} \eta(T) \phi(T)\right] \\
& \quad=2 D_{\mathrm{B}}^{\mathrm{Fe}_{2} \mathrm{~B}}\left(C_{\mathrm{up}}^{\mathrm{Fe}_{2} \mathrm{~B}}-C_{\mathrm{low}}^{\mathrm{Fe}_{2} \mathrm{~B}}\right) \phi(T)\left[\left(k_{2}-k_{1} \eta(T)\right]\right. \\
& -2 \eta(T) \phi(T) D_{\mathrm{B}}^{\mathrm{DZ}}\left(C_{\mathrm{up}}^{\mathrm{DZ}}-C_{\mathrm{low}}^{\mathrm{DZ}}\right)\left[k_{1}-k_{\mathrm{FeB}} \phi(T)\right], \\
& {\left[k_{2} \phi(T) \eta(T)-k_{\mathrm{FeB}}\right]\left[k_{2}-k_{1} \eta(T)\right]=4 D_{\mathrm{B}}^{\mathrm{DZ}} \phi(T) \eta(T),}
\end{aligned}
$$

where

$$
\phi(T)=\frac{\beta(T)}{\alpha(T)},
$$

and

$$
\eta(T)=\frac{\gamma(T)}{\beta(T)},
$$

with

$$
\begin{aligned}
& \alpha(T)=\left(1-t_{0}^{\mathrm{FeB}}(T) / t\right)^{-0.5}, \\
& \beta(T)=\left(1-t_{0}^{\mathrm{Fe}_{2} \mathrm{~B}}(T) / t\right)^{-0.5}, \\
& \gamma(T)=\left(1-t_{0}^{\mathrm{DZ}}(T) / t\right)^{-0.5} .
\end{aligned}
$$

The obtained system of equations can be solved, using the Newton-Raphson method [12], to determine the three unknowns $\left(k_{\mathrm{FeB}}, k_{1}\right.$ and $\left.k_{2}\right)$ which are the corresponding values of the parabolic growth constants at each growing phase interface. The temperature-dependent parameters $\alpha(T), \beta(T)$ and $\gamma(T)$ are given by Eqs. (32), (33) and (34) (see Fig. 2):

$$
\begin{aligned}
& \alpha(T)=-3 \cdot 73 \times 10^{-3} T+5.8282, \\
& \beta(T)=-3 \times 10^{-3} T+4.8680
\end{aligned}
$$

and

$$
\gamma(T)=-2 \cdot 34 \times 10^{-3} T+3.9504 .
$$

The high boriding temperatures result in shorter incubation times [13]. It is also possible to estimate the thickness (in $\mu \mathrm{m}$ ) of each layer using Eqs. (35), (36) and (37):

$$
\begin{aligned}
& u=\frac{k_{\mathrm{FeB}} t^{0.5}}{\alpha(T)}, \\
& l=\left[\frac{k_{1}}{\beta(T)}-\frac{k_{\mathrm{FeB}}}{\alpha(T)}\right] t^{0.5}, \\
& z=\left[\frac{k_{2}}{\gamma(T)}-\frac{k_{1}}{\beta(T)}\right] t^{0.5} .
\end{aligned}
$$

Finally, the borided layer thickness $(w)$ can be estimated from Eq. (38):

$$
w=\frac{k_{2} t^{0.5}}{\gamma(T)} \text {. }
$$

\section{Experimental validation of the model and discussion of results}

The experimental results obtained on the borided AISI 316 stainless steel [4] were used to validate the developed diffusion model. In their experimental work, the powder-pack boriding was carried out at different temperatures $(1123,1173,1223$, and $1273 \mathrm{~K})$ during variable treatment

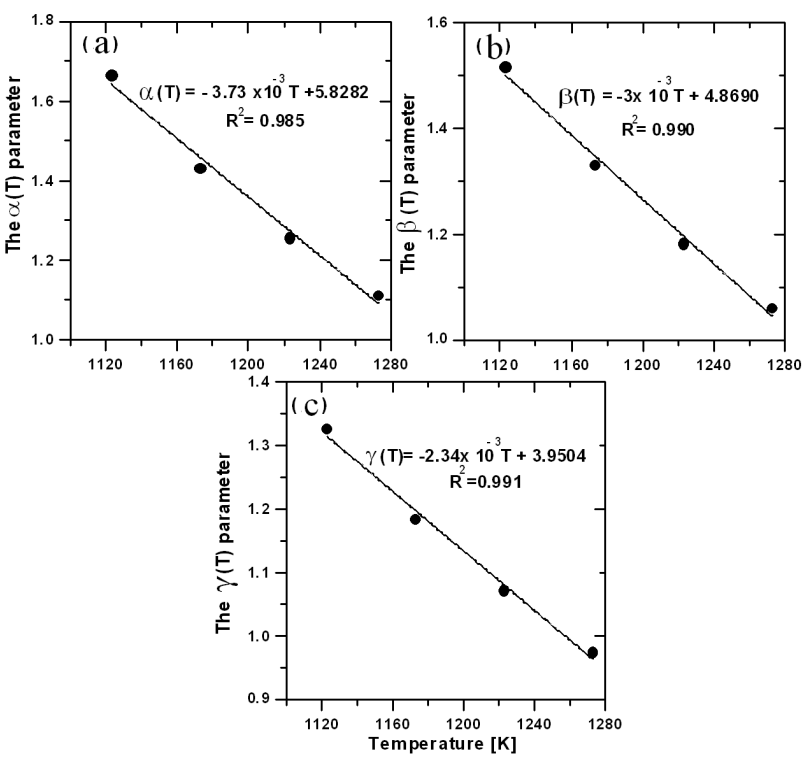

Fig. 2. (a) The $\alpha(T)$ parameter versus the boriding temperature, (b) the $\beta(T)$ parameter versus the boriding temperature, (c) the $\gamma(T)$ parameter as a function of the boriding temperature.

times $(2,4,6,8$, and $10 \mathrm{~h})$. Fifty measurements were done on different cross-sections of the borided samples to evaluate the thicknesses of the $\mathrm{FeB}$ and $\mathrm{Fe}_{2} \mathrm{~B}$ boride layers and the diffusion zone thickness. The developed computer code, written in Matlab (version 6.5), employs the following parameters as input data: (the temperature, the treatment time, the upper and lower limits of boron concentration in each iron boride, the upper and lower limits of boron concentration within the diffusion zone, the diffusion coefficients of boron in the $\mathrm{FeB}$ and $\mathrm{Fe}_{2} \mathrm{~B}$ phases and the mobility of boron in the diffusion zone as well as the expressions of the $\phi(T)$ and $\eta(T)$ parameters). The outputs of the computer code are the parabolic growth constant at each growth front and the thicknesses of the $\mathrm{FeB}$ and $\mathrm{Fe}_{2} \mathrm{~B}$ layers and the diffusion zone thickness as a function of the boriding parameters. To determine the experimental values of the parabolic growth constants at each growth front, it is required to plot the squared layers thicknesses versus the treatment time. The generated linear curves provide the slopes that correspond to the values of the squared parabolic growth constants at each growth front. The incubation times deduced from these linear curves were used to determine the temperature dependence of the $\phi(T)$ and $\eta(T)$ parameters involved in the model.

Tables I, II and III give a comparison between the simulated values in terms of the parabolic growth constants at each phase interface and the values obtained experimentally [4]. A good concordance was observed between the experiments and the simulation calculations in the temperature range of 1123-1273 K and for the upper boron content in the FeB phase $(=16.40 \mathrm{wt} \%)$. In 
TABLE I

Experimental and simulated values [4] of the parabolic growth constants at the $\left(\mathrm{FeB} / \mathrm{Fe}_{2} \mathrm{~B}\right)$ interface $k_{\mathrm{FeB}}$ in the temperature range of $1123-1273 \mathrm{~K}$ for $C_{\mathrm{up}}^{\mathrm{FeB}}=$ $16.40 \mathrm{wt} \% \mathrm{~B}$.

\begin{tabular}{|c|c|c|}
\hline $\begin{array}{c}T \\
{[\mathrm{~K}]}\end{array}$ & $\begin{array}{c}\text { Experimental } \\
\text { growth constants } \\
{\left[\mu \mathrm{m} \mathrm{s}^{-0.5}\right]}\end{array}$ & $\begin{array}{c}\text { Predicted } \\
\text { growth constants } \\
k_{\mathrm{FeB}}\left[\mu \mathrm{m} \mathrm{s}^{-0.5}\right]\end{array}$ \\
\hline 1123 & 0.068 & 0.069 \\
\hline 1173 & 0.118 & 0.110 \\
\hline 1223 & 0.157 & 0.168 \\
\hline 1273 & 0.241 & 0.247 \\
\hline
\end{tabular}

TABLE II

Experimental and simulated values [4] of the parabolic growth constants at the $\left(\mathrm{Fe}_{2} \mathrm{~B} /\right.$ substrate $)$ interface $k_{1}$ in the temperature range of $1123-1273 \mathrm{~K}$ for $C_{\mathrm{up}}^{\mathrm{FeB}}=$ $16.40 \mathrm{wt} \% \mathrm{~B}$.

\begin{tabular}{c|c|c}
\hline \hline$T[\mathrm{~K}]$ & $\begin{array}{c}\text { Experimental } \\
\text { growth constants } \\
{\left[\mu \mathrm{m} \mathrm{s}^{-0.5}\right]}\end{array}$ & $\begin{array}{c}\text { Predicted } \\
\text { growth constants } \\
k_{1}\left[\mu \mathrm{m} \mathrm{s}^{-0.5}\right]\end{array}$ \\
\hline 1123 & 0.145 & 0.152 \\
1173 & 0.254 & 0.241 \\
1223 & 0.337 & 0.367 \\
1273 & 0.542 & 0.543
\end{tabular}

Table IV, the predicted values of the thickness of FeB and $\mathrm{Fe}_{2} \mathrm{~B}$ layers and those of the diffusion zone thickness were compared to the experimentally determined values for the temperature of $1243 \mathrm{~K}$ and treatment times of 3 and $5 \mathrm{~h}$. A good agreement was then observed between the experimental data and the simulation results for this set of boriding conditions.

In addition, the simulation results obtained from Eq. (38) about the thicknesses of the borided layers are compared with the experimental values to validate the diffusion model in the temperature range of 1123-1273 K, as illustrated in Table V. It is seen that the predicted values agree with the simulated ones.

The temperature dependence of the simulated parabolic growth constants at the three diffusion fronts: $\left(\mathrm{FeB} / \mathrm{Fe}_{2} \mathrm{~B}\right),\left(\mathrm{Fe}_{2} \mathrm{~B} /\right.$ diffusion zone) and (diffusion zone/

TABLE III

Experimental [4] and simulated values of the parabolic growth constants at the (diffusion zone/substrate) interface $k_{2}$ in the temperature range of 1123-1273 K for $C_{\mathrm{up}}^{\mathrm{FeB}}=16.40 \mathrm{wt} \% \mathrm{~B}$.

\begin{tabular}{|c|c|c|}
\hline $\begin{array}{c}T \\
{[\mathrm{~K}]}\end{array}$ & $\begin{array}{c}\text { Experimental } \\
\text { growth constants } \\
{\left[\mu \mathrm{m} \mathrm{s}^{-0.5}\right]}\end{array}$ & $\begin{array}{c}\text { Predicted } \\
\text { growth constants } \\
k_{2}\left[\mu \mathrm{m} \mathrm{s}^{-0.5}\right]\end{array}$ \\
\hline 1123 & 0.271 & 0.278 \\
\hline 1173 & 0.407 & 0.395 \\
\hline 1223 & 0.530 & 0.549 \\
\hline 1273 & 0.737 & 0.752 \\
\hline
\end{tabular}

substrate) is depicted in Fig. 3 for three different upper boron contents in the FeB phase.

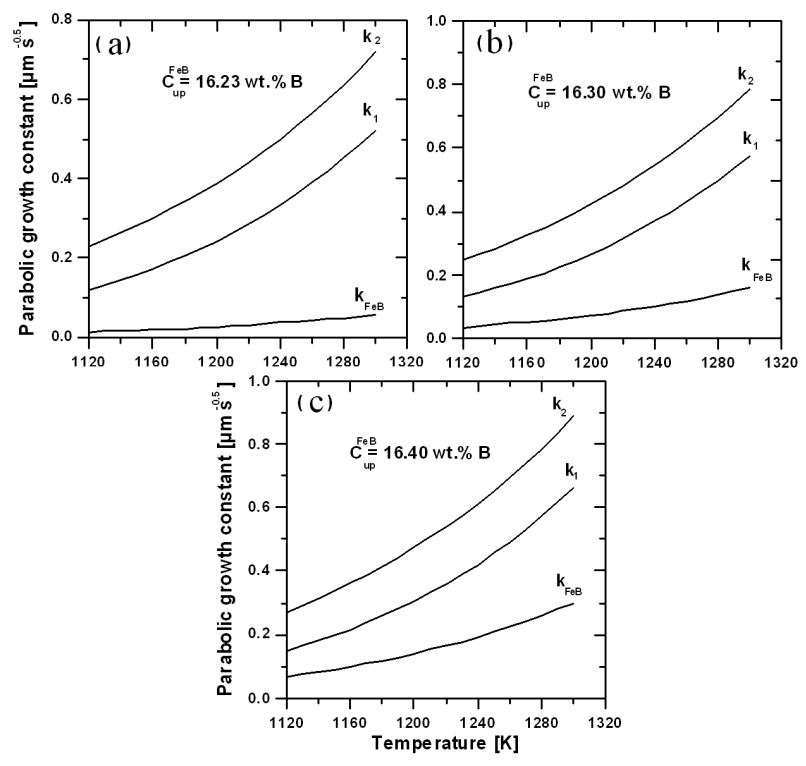

Fig. 3. Temperature dependence of the parabolic growth constants at the three growth fronts for different upper boron contents in the $\mathrm{FeB}$ phase. (a) $16.25 \mathrm{wt} \% \mathrm{~B}$, (b) $16.30 \mathrm{wt} \% \mathrm{~B}$, and (c) $16.40 \mathrm{wt} \% \mathrm{~B}$.

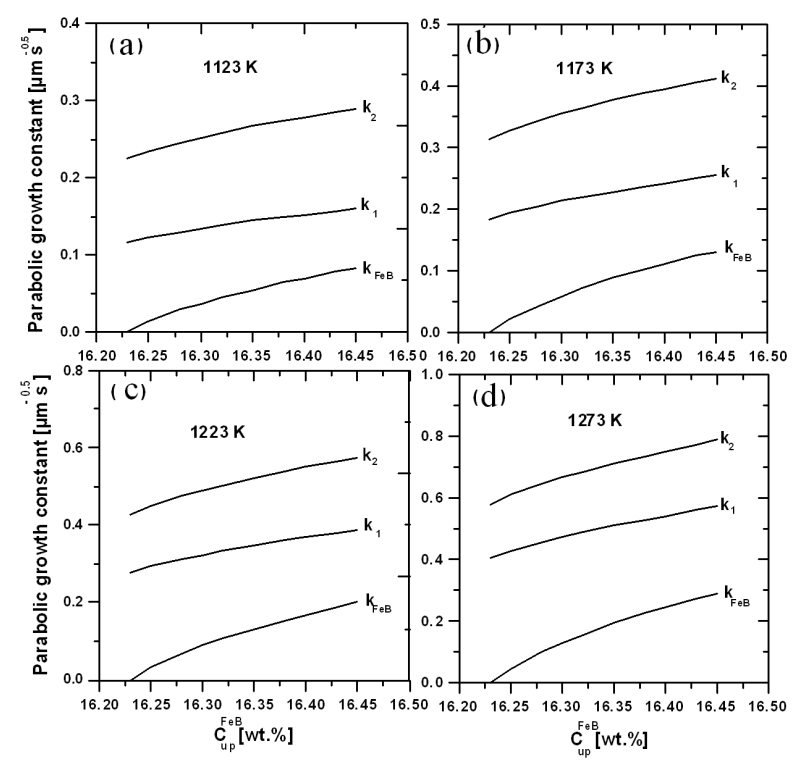

Fig. 4. Evolution of the parabolic growth constants at the three growth fronts versus the upper boron content in the FeB phase for different temperatures: (a) $1123 \mathrm{~K}$, (b) $1173 \mathrm{~K}$, (c) $1223 \mathrm{~K}$, and (d) $1273 \mathrm{~K}$.

The growth kinetics of the borided layers is enhanced as the process temperature increases; this fact is ascribed to the increase of the value of the upper boron content in the FeB phase. It is seen that the simulated values of the parabolic growth constants at the (diffusion zone/substrate) interface change speedily with the process tem- 
perature in comparison with those of the two interfaces: $\left(\mathrm{FeB} / \mathrm{Fe}_{2} \mathrm{~B}\right)$ and $\left(\mathrm{Fe}_{2} \mathrm{~B} /\right.$ diffusion zone).

The evolution of the simulated parabolic growth constants at the three growth fronts versus the upper boron content in the FeB phase at different temperatures is shown in Fig. 4.

The growth kinetics of the borided layers is affected by the increase of the boriding temperature. So the boron diffusion in powder-pack boriding is influenced by the contact surface between the boriding agent and the substrate. Thus, a fine particle of the boriding powder allows for better diffusion of the atomic boron into the material surface. An increase of the upper boron content in the FeB phase has a major effect on the boriding kinetics.

TABLE IV

Experimental [4] and simulated values of the boride layer thickness and those of the diffusion zone at the temperature of $1243 \mathrm{~K}$ for 3 and $5 \mathrm{~h}$ of treatment times.

\begin{tabular}{c|c|c|c|c|c|c}
\hline \hline \multirow{2}{*}{ Time $[\mathrm{h}]$} & $\begin{array}{c}\text { Experimental } \\
\text { FeB layer }\end{array}$ & $\begin{array}{c}\text { Simulated } \\
\text { FeB layer }\end{array}$ & $\begin{array}{c}\text { Experimental } \\
\mathrm{Fe}_{2} \mathrm{~B} \text { layer }\end{array}$ & $\begin{array}{c}\text { Simulated } \\
\mathrm{Fe}_{2} \mathrm{~B} \text { layer }\end{array}$ & $\begin{array}{c}\text { Experimental } \\
\text { diffusion zone }\end{array}$ & $\begin{array}{c}\text { Estimated } \\
\text { diffusion zone }\end{array}$ \\
\cline { 2 - 7 } & \multicolumn{7}{|c}{ thickness $[\mu \mathrm{m}]$} \\
\hline 3 & $20.3 \pm 1.0$ & 17.20 & $22.2 \pm 1.3$ & 22.15 & $23.1 \pm 1.5$ & 22.90 \\
5 & $28.7 \pm 1.7$ & 22.21 & $29.67 \pm 1.1$ & 28.60 & $30.45 \pm 2.1$ & 29.56
\end{tabular}

TABLE V

Experimental $\left(w_{\exp }\right)$ and simulated values $\left(w_{\text {sim }}\right)$ of the borided layer thickness for various treatment times and boriding temperatures.

\begin{tabular}{c|c|c|c|c|c|c|c|c}
\hline \hline Time $[\mathrm{h}]$ & \multicolumn{2}{|c|}{$1123 \mathrm{~K}$} & \multicolumn{2}{|c|}{$1173 \mathrm{~K}$} & \multicolumn{2}{|c|}{$1223 \mathrm{~K}$} & \multicolumn{2}{c}{$1273 \mathrm{~K}$} \\
\cline { 2 - 8 } & $w_{\exp }[\mu \mathrm{m}]$ & $w_{\text {sim }}[\mu \mathrm{m}]$ & $w_{\exp }[\mu \mathrm{m}]$ & $w_{\text {sim }}[\mu \mathrm{m}]$ & $w_{\exp }[\mu \mathrm{m}]$ & $w_{\text {sim }}[\mu \mathrm{m}]$ & $w_{\exp }[\mu \mathrm{m}]$ & $w_{\text {sim }}[\mu \mathrm{m}]$ \\
\hline 2 & 17.38 & 17.83 & 28.64 & 27.80 & 41.31 & 42.79 & 64.36 & 65.67 \\
4 & 24.58 & 25.22 & 40.51 & 39.31 & 58.42 & 60.51 & 91.02 & 92.87 \\
6 & 30.11 & 30.89 & 49.61 & 48.15 & 71.55 & 74.12 & 111.48 & 113.75 \\
8 & 34.77 & 35.67 & 57.29 & 55.60 & 82.62 & 85.58 & 128.73 & 131.35 \\
10 & 38.87 & 39.88 & 64.05 & 62.16 & 92.37 & 95.68 & 143.92 & 146.85
\end{tabular}

\section{Conclusion}

The growth kinetics of the $\left(\mathrm{FeB} / \mathrm{Fe}_{2} \mathrm{~B}\right)$ bilayer and the diffusion zone generated by the powder-pack boriding were predicted using a diffusion model. The developed computer code, based on the present model, consists in solving a set of mass balance equations at the three growth fronts: $\left[\left(\mathrm{FeB} / \mathrm{Fe}_{2} \mathrm{~B}\right),(\mathrm{FeB} /\right.$ diffusion zone $)$ and (diffusion zone/substrate)] under specified boriding conditions. Two temperature-dependent parameters $\phi(T)$ and $\eta(T)$ were incorporated in the diffusion model to consider the effect of the incubation times during the formation of iron borides and the diffusion zone. For the value of the upper boron content in the FeB phase of $16.40 \mathrm{wt} \%$, a good agreement was obtained when comparing the values of experimental parabolic growth constants to the predicted ones for each phase interface. Moreover, the present model was also capable of predicting the thicknesses of $\mathrm{FeB}$ and $\mathrm{Fe}_{2} \mathrm{~B}$ layers as well as the thicknesses of diffusion zone at various treatment times and boriding temperatures. The simulated values were in good agreement with the experimental borided layers thicknesses.

\section{Acknowledgments}

This work was carried out in the framework of CNEPRU project under the code number J0300220100093 of the Algerian Ministry of High Education and Scientific Research.

\section{References}

[1] A.K. Sinha, J. Heat Treat. 4, 437 (1991).

[2] M. Carbucicchio, G. Palombarini, J. Mater. Sci. Lett. 6, 1147 (1987).

[3] M. Keddam, Appl. Surf. Sci. 257, 2004 (2011).

[4] I. Campos-Silva, M. Ortiz-Domínguez, O. BravoBárcenas, M.A. Doñu-Ruiz, D. Bravo-Bárcenas, C. Tapia-Quintero, M.Y. Jiménez-Reyes, Surf. Coat. Technol. 205, 403 (2010).

[5] H. Okamoto, J. Phase Equilib. Diff. 25, 297 (2004).

[6] B. Hallemans, P. Wollants, J.R. Roos, Z. Metallkde 85, 676 (1994).

[7] T. Van Rompaey, K.C. Hari Kumar, P. Wollants, J. Alloys Comp. 334, 173 (2002).

[8] M. Keddam, Appl. Surf. Sci. 253, 757 (2006).

[9] L.G. Yu, X.J. Chen, K.A. Khor, Acta Mater. 53, 2361 (2005).

[10] T.B. Massalski, Binary Alloys Phase Diagrams, 2nd ed., ASM International, Metals Park, OH 1990.

[11] U. Roy, Acta Metall. 16, 243 (1968).

[12] W.H. Press, B.P. Flannery, S.A. Teukolsky, Numerical Recipes in Pascal: the Art of Scientific Computing, Cambridge University, Cambridge 1989.

[13] M. Ortiz-Domínguez, I. Campos-Silva, E. HernándezSánchez, J.L. Nava-Sánchez Martínez-Trinidad, M.Y. Jiménez-Reyes, O. Damián-Mejía, Int. J. Mater. Res. 102, 429 (2011). 